\section{AB0966 THE CLINICAL OBSERVATION OF IMMUNOADSORPTION IN TREATMENT OF CHILDREN WITH REFRACTORY AUTOIMMUNE DISEASES}

P. Zeng ${ }^{1}, \mathrm{H}$. Zeng $^{2} .{ }^{1}$ Department of Pediatric Allergy, Immunology and Rheumatolog, Guangzhou Women and Children's Medical Center, Guangzhou; ${ }^{2}$ Department of Pediatric Allergy, Immunology and Rheumatology, Guangzhou Women and Children's Medical Center, Gungzhou, China

Objectives: Explore the clinical efficacy and safety of the immunoadsorption assisted treatment of children with refractory autoimmune diseases.

Methods: Use HA280 type resin perfusion machine for four times of whole blood immunoadsorption treatment for one case of a 4-year-old child combined with severe dermatomyositis and pulmonary infection, one case of 9-year-old child with severe allergic purpura combined with gastrointestinal bleeding, intestinal perforation, after intestinal tract partial hepatectomy, one case of 11-year-old child with systemic juvenile idiopathic arthritis combined with head and facial cellulites and macrophage activation syndrome. Observe the improvement of its clinical manifestations, serum immunoglobulin, complement, liver and kidney function, myocardial enzymes, autoantibodies.

Results: The children's signs and symptoms improved significantly after treatment of whole blood immunoadsorption, the sensitivity of the adrenal cortex hormones increased, liver and kidney function, myocardial enzymes improved, the levels of serum IGG descended, complement (C3, C4) rose, anti-cyclic citrullinated peptide (CCP) was negative.

Conclusions: The whole blood perfusion immunity adsorption treatment is able to to reduce blood plasma IGG, improvement complement C3 and C4 level, eliminates anti-CCP immune body in vivo, reduce the cardiac muscle zymogram and the liver enzyme in a short time, increase sensitivity to the adrenal cortex hormone, alleviate immunological disease's symptom in active stage, have the affirmative function to make the baby pass the dangerous period safely. The child whole blood fills the class immunity adsorption not to present the untoward effect. No untoward effect happened.

Disclosure of Interest: None declared

DOI: 10.1136/annrheumdis-2017-eular.2119

\section{AB0967 CLINICAL, LABORATORY PROFILES AND LONG-TERM OUTCOME OF JUVENILE CUTANEOUS PAN: A SINGLE CENTER EXPERIENCE}

R.A. Castellanos-Moreira ${ }^{1}$, J.M. Mosquera ${ }^{1}$, S.C. Rodriguez-Garcia ${ }^{1}$, J. Calzada ${ }^{1}$, A. Vicente ${ }^{2}$, E. Iglesias ${ }^{1}$, R. Bou ${ }^{1}$, J. Anton ${ }^{1} .{ }^{1}$ Rheumatology;

${ }^{2}$ Dermatology, Hospital Sant Joan de Déu, Barcelona, Spain

Background: Cutaneous polyarteritis nodosa (CPAN) is an immune complexmediated rare disease that affects small and medium sized vessels in the dermis and subcutaneous tissue.

The clinical course is characterized by periodic exacerbations and remissions that may persist for many years. Most patients respond to NSAIDs and glucocorticoids (GC), whereas some may require DMARDs and/or immunomodulatory therapy.

Objectives: To describe the diferrent clinical patterns, laboratory findings and long term outcomes of juvenile cPAN in a tertiary care hospital.

Methods: Retrospective observational study, including all patients diagnosed with cPAN between 2002-2016. Diagnosis relied on clinical features confirmed by histological study. Recorded data included clinical features, laboratory results and long-term outcomes.

Results: 10 children were included ( 7 female), mean age at onset was 9.9 years $(r: 4.1-16.3)$. Delay from symptoms onset to biopsy confirmed diagnosis was $2 \pm 2.3$ months; 4 patients underwent a second biopsy due to inconclusive results in the first performed.

Clinical features included cutaneous (100\%) and osteomuscular involvement $(50 \%)$, fever $(40 \%)$, neuropathy $(10 \%)$ and weight loss (10\%). Reported cutaneous symptoms were 8 patients with nodules, 4 livedo, 4 purpura, 1 ulcer and 1 necrosis. Most lesions were localized in the lower limbs (8), even though it was also reported in upper limbs (3) and trunk (3). Most cases exhibited raised CRP, ESR and leukocyte count with a mean of $26.4 \pm 47.9(\mathrm{mg} / \mathrm{L}), 27.7 \pm 29.7(\mathrm{~mm} / \mathrm{h})$, and $8.6 \pm 5.3$ (x $\left.10^{9} / \mathrm{L}\right)$ respectively.

As first line therapy, all patients received GC and 6 NSAIDs. 8 were given a DMARD such as HCQ or MTX. Due to persistent activity or relapse, rescue treatment with pulse-GC $(20 \%)$, MMF $(10 \%)$ or IVIG $(20 \%)$ was instituted. Only 1 patient received penicillin prophylaxis due to relapses associated with streptococcal infection.

Mean follow-up was 3.9 years (r: 1.1-10.4). 4 patients had a monophasic disease, six suffered $\geq 2$ relapses. At last follow-up 9 patients were on remission, even though 3 were off-therapy. No complications were reported.

Conclusions: Clinical and laboratory findings in our series was similar to previous reports. However, our patients presented a greater number of relapses and DMARDs requirement.

Disclosure of Interest: None declared

DOI: 10.1136/annrheumdis-2017-eular.4120

\section{AB0968 HYPOVITAMINOSIS D IN JUVENILE IDIOPATHIC ARTHRITIS: PREVALENCE AND RELATED FACTORS}

R. Galindo Zavala ${ }^{1}$, L. Martín Pedraz ${ }^{2}$, E. Núñez Cuadros $^{3}$, G. Díaz-Cordovés Rego ${ }^{4}$, A.L. Urda Cardona ${ }^{2} .{ }^{1}$ Paediatric Rheumatology; ${ }^{2}$ Paediatrics;

${ }^{3}$ Universitary Regional Malaga Hospital, Malaga, Spain; ${ }^{4}$ Rheumatology, Universitary Regional Malaga Hospital, Malaga, Spain

Background: 25hydroxy-vitamin D not only plays a key role in calcium homeostasis, but also has antiinflammatory and immunomodulatory properties. Hypovitaminosis D prevalence in children suffering from Juvenile Idiopathic Arthritis (JIA) ranges from $6 \%$ to $30 \%$ according to different publications.

Objectives: Evaluate hypovitaminosis D prevalence in JIA pediatric patients in Spain and assess involved factors.

Methods: Observational cross-sectional study in JIA Spanish patients from 4 to 15 years, monitored by a Pediatric Rheumatology Unit. Monoarticular forms and patients with other chronic diseases or receiving different treatments from those indicated for JIA were excluded.

Anthropometric, clinical and treatment data were recorded. Bone metabolism parameters and validated diet (KIDMED) and exercise (PAQ-C/PAQ-A) questionnaires were obtained.

Hypovitaminosis D was defined as 25 hydroxy-vitamin D plasma levels lower than $30 \mathrm{ng} / \mathrm{ml}$

Results: 76 children participated. Their characteristics are included in table 1.

The population's prevalence estimation of hypovytaminosis $D$ in children with JIA was $16-35 \%$ (Cl 95\%).

We found no relationship between 25 hydroxy-vitamin D levels and sex, JIA subtype neither duration or dose of systemic glucocorticoids.

In bivariate analysis we found direct association between hypovitaminosis $D$ and Body Mass Index percentile (BMIp) $(\mathrm{p}=0,05)$, received dose of prednisone $(p=0,03)$ and clinical activity duration $(p=0,04)$; and an inverse relationship with physical activity level $(p=0,04)$.

In multivariate analysis, relationship between hypovitaminosis $\mathrm{D}$ and $\mathrm{BMlp}(\mathrm{B}$ 0,$024 ; p$ 0,016) and with disease activity (B 0,015; $p$ 0,01) were maintained. Moreover, we found an inverse association with biological disease-modifiying antirheumatic drugs (B-4,69; $\mathrm{p} 0,048)$, specifically with anti-tumoral necrosis factor $\alpha($ antiTNF $\alpha)(B-4,7 ;$ p 0,042$)$

\begin{tabular}{|c|c|c|}
\hline \multicolumn{3}{|c|}{ PATHENTS CHARACTERITCS (N-76) } \\
\hline \multicolumn{2}{|c|}{ Gender (Mate), $n(\%)$} & $23(30,3)$ \\
\hline \multicolumn{2}{|c|}{ Age (years), median (IR) } & $10,83(8,52-13,54)$ \\
\hline \multicolumn{2}{|c|}{ 250H-Vitamin D $(\mathrm{ng} / \mathrm{mL})$ mean $(+/-\mathrm{SD})$} & $\begin{array}{l}34,05 \mathrm{ng} / \mathrm{ml}, \\
(8,90 \mathrm{ng} / \mathrm{ml})\end{array}$ \\
\hline \multicolumn{3}{|c|}{ DISEASE CHARACTERISTICS $(\mathrm{N}=76)$} \\
\hline JIA subtype, $\mathrm{n}(\%)$ & $\begin{array}{l}\text { Systemic } \\
\text { Persistent oligoarticular } \\
\text { Extended oligoarticular } \\
\text { Positive RF polyarticular } \\
\text { Negative RF Polyarticular }\end{array}$ & $\begin{array}{l}9(11,8) \\
35(46,1) \\
12(15,8) \\
1(1,3) \\
19(25,0)\end{array}$ \\
\hline \multicolumn{2}{|c|}{ Duration disease (ycors), median (IR) } & $6,55(0,29,9,45)$ \\
\hline \multicolumn{2}{|c|}{ Inflammatory activity duration (days), median (IR) } & $385,0(246,75-761,25)$ \\
\hline \multicolumn{3}{|c|}{ RECEIVED TREATMENTS (N=76)* } \\
\hline \multicolumn{2}{|r|}{ Systemic GC $n(\%)$} & $61(80,2)$ \\
\hline \multicolumn{2}{|c|}{ 6C: treatmeat duration (days), median (IR) * (naBs) } & $125,00(66,00-179,00)$ \\
\hline \multicolumn{2}{|c|}{ Meas GC dose (mg/kg/day), median (IR) } & $0,276(0,169-0,457)$ \\
\hline \multicolumn{2}{|c|}{ Syothetic DMARDs treatment, $n(\%)$} & $39(513)$ \\
\hline \multicolumn{2}{|c|}{ Biological DMARDs treatment, n (\%) } & $21(27.6)$ \\
\hline $\begin{array}{c}\text { Biological } \\
\text { DMARDs } \\
\text { treatment } \\
\text { subtype, } n(\%)\end{array}$ & $\begin{array}{l}\text { Anti-TNF } \alpha \\
\text { Anti-HL1 } \\
\text { Anti-H6 }\end{array}$ & $\begin{array}{l}\text { is }(19,7) \\
4(5,2)\end{array}$ \\
\hline \multicolumn{3}{|c|}{ 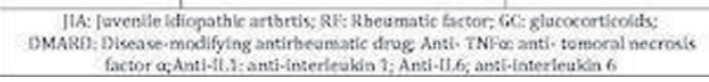 } \\
\hline
\end{tabular}

Conclusions: Hypovitaminosis D prevalence in our population is similar to previously described.

JIA patients with higher BMlp have more hypovitaminosis D, as it has been reported in other inflammatory diseases.

A direct relationship exists between inflammatory activity and vitamin D, but we need more studies to asses if one is cause or consecuence of the other.

Patients treated with antiTNF have better plasma levels of 25 hydroxy-vitamin D, this can be explained because these drugs may increase 25 hydroxy-vitamin $D$ 